\title{
Calculation of rear brake power and rear brake work during skidding on paved and gravel cycling surfaces
}

\author{
Matthew C Miller ${ }^{1}$, Aden A Tully ${ }^{2}$, Adam M Miller ${ }^{1}$, Stephen R Stannard ${ }^{1}$ and Philip W Fink ${ }^{1} \bowtie$
}

\begin{abstract}
The use of a brake power meter at each wheel of a bicycle is a valid means to calculate energy losses due to braking. However, methodology utilizing the torque and angular velocity at each wheel independently are not able to reflect energy lost to braking when the rear wheel is skidding. This study tested the possibility of using the angular velocity of the front wheel, but the torque of the rear brake, to calculate rear brake power. Two cyclists completed 100 braking trials across three days on a mixture of paved and gravel surfaces with a mixture of skidding and non-skidding. The estimated total energy removed from the bicycle-rider system was calculated as the sum of brake work and estimates of drag and rolling resistance. This energy removed from the bicycle-rider system displayed a strong positive relationship with the change in kinetic energy of the bicycle-rider system during braking on paved $\left(r^{2}=0.955 ; p<0.0001\right)$ and gravel surfaces paved $\left(r^{2}=0.702 ; p<0.0001\right)$. There was no difference between these measurements overall $(p<0.05)$, however there is some error of measurement when skidding on gravel. The findings in the present investigation indicate that rear brake work is underestimated when using the angular velocity at the rear wheel during skidding, but that utilising the angular velocity of the front wheel is a valid means of calculating rear brake power. Care should be taken when skidding on gravel as it is difficult to assess the linear velocity of the bicycle.
\end{abstract}

Keywords: power meter, brake power meter, cycling, skidding

Contact email: p.fink@massey.ac.nz (Philip W Fink)

${ }^{1}$ School of Sport \& Exercise, Massey University, Palmerston North, New Zealand

2 Department of Exercise Science, East Stroudsburg University, East Stroudsburg, PA, United States

Received: 17 May 2019. Accepted: 27 February 2020.

\section{Introduction}

Until recently, it has been impossible to quantify efficiencies in bicycle riding outside of propulsive and physiological variables. However, a bicycle brake power meter has recently been validated that can measure the rate of energy removed from the bicycle rider system through the rider-induced interaction between the brake caliper and the rotor (Miller et al, 2017a). This brake power meter has since been utilised to calculate the brake work and rate of brake work (brake power) during actual cycling (Miller et al., 2018a; Impellizerri \& Marcora, 2007). These investigations henceforth indicated the importance of describing and understanding braking patterns during Olympic-format cross-country mountain bike (XCO-MTB) racing, and supported the idea that braking did indeed affect performance. These reports are important because they addressed questions concerning bicycle handling efficiency that had previously remained unquantified (Miller et al., 2017b; Miller et al., 2018b; Chidley et al., 2014; Hurst et al., 2006; Macdermid et al., 2017).
The first published study using a brake power meter introduced the importance of measuring braking during cycling and then went on to validate energy losses due to braking when compared to the change in kinetic energy of the bicycle-rider system (Miller et al., 2017a). Later, an initial descriptive study in braking during XCO-MTB supported evidence that propulsive power was important for a high level of performance, but purported that analyses of performance were enhanced with the addition of a brake power meter (Miller et al., 2018a). Specifically, relative propulsive power output was combined with brake work and brake time in a multiple regression model that was strongly associated with XCO-MTB lap time. This study purported that riders could save energy by adopting more efficient braking and propulsive strategies, and that even elite riders may be able to ride more efficiently at the same physical ouput. A follow-up study compared trained and untrained groups on a short descent with a turn, and highlighted that measures of braking alone helped to describe the performance characteristics of each group (Miller et al., 2018b). While it was not surprising that untrained cyclists travelled slower, analyses indicated that this lower speed was due to increased brake work and brake time, but reduced brake power.

During these initial analyses, there were no instances recorded of the front wheel locking up or the front tire skidding, which was apparent by inspection of angular velocity at the front wheel. This observance supported practitioner philosophies which contend that locking the 
front wheel results in losing control of the bicycle (Lopes \& McCormack, 2010). Occasionally however, the rear wheel brake was locked which resulted in the skidding of the rear tire. The total duration of this skidding equated to $1.1 \mathrm{~s}$ per lap on a $1.24 \mathrm{~km}$ crosscountry mountain bike race track (Miller et al., 2018a). While the benefits or detriments of skidding and performance are not well-understood, previously described methods (Miller et al., 2017a; Miller et al., 2018a; Miller et al., 2018b) utilised to calculate brake power were not able to account for friction-related energy losses experienced when the rear wheel is skidding. In these investigations, brake power $\left(P_{B}\right)$ was calculated at each brake as the product of brake torque times the angular velocity of the wheel given,

$$
P_{B}=\tau \omega
$$

(Eq. 1)

Where, $\tau$ is torque and $\omega$ is angular velocity.

The product of $\tau$ and $\omega$ at each brake was intergrated to calculate brake work $\left(W_{B}\right)$ given,

$$
W_{B}=\int \tau \omega
$$$$
\text { (Eq. 2) }
$$

In this case, any time the wheel stops spinning, the resultant $P_{B}$ and $W_{B}$ are zero, despite any recorded torque. However, it is obvious that energy is being removed from the bicycle-rider system during skidding, being converted to heat, noise, and physical work done on the terrain surface. Therefore, to ensure accurate $P_{B}$ and $W_{B}$ readings, this energy loss must be accounted for. Since Eq. 1 is not accurate for calculating $P_{B}$ and $W_{B}$ during skidding, it may be possible to calculate $P_{B}$ and $W_{B}$ as the product of force and velocity instead. In this case a combination of measurements from both the front and rear wheels can be utilized due to them both being connected to the same bicycle.

If we assume that the front wheel does not skid (since this would result in a loss of control of the bicycle), the linear velocity of the bicycle can be estimated by measuring the angular velocity of the front wheel given,

$$
\begin{gathered}
V=\omega_{\mathrm{f}} r \\
(\text { Eq. 3) }
\end{gathered}
$$

Where, $\mathrm{v}$ is velocity, $\omega_{\mathrm{f}}$ is the angular velocity of the front wheel, and $r$ is the radius of the front wheel. The use of the front wheel for the measurement of velocity is akin to traditional bicycle wheel magnets and can be done without relying on GPS (Wing et al., 2005).

To be able to calculate the energy lost in skidding we must calculate the frictional force at the tire-terrain interface. This force can be calculated given,

$$
\begin{aligned}
& \mathrm{F}=\frac{\tau_{\mathrm{r}}}{r} \\
& (\text { Eq. } 4)
\end{aligned}
$$

Where, $\mathrm{F}$ is the frictional force between the skidding rear tire and the ground, $\tau_{\mathrm{r}}$ is the torque at measured at the brake of the rear wheel and $r$ is the radius of the rear wheel.

Therefore, since power is the product of force and velocity,

$$
\mathrm{F} V=\frac{\tau_{\mathrm{r}}}{r}\left(\omega_{\mathrm{f}} r\right)
$$

This can be simplied to,

$$
P_{B}=\tau_{\mathrm{r}} \omega_{\mathrm{f}}
$$

(Eq. 6)

While Eq. 5 is theoretically valid, it is not currently known if this calculation will provide valid rear brake power recordings during actual field use. Therefore, the aim of the present study was to determine the validity of brake power and brake work measurements during skidding by calculating brake power as the product of brake torque at both the front and rear wheels, but measuring angular velocity at only the front wheel at a range of skid distances. It was hypothesised that this estimated brake work calculated during braking events with skids and without skids would be strongly associated with the change in kinetic energy of the bicycle-rider system on both road and off-road surfaces.

\section{Methods}

Two cyclists (178.0 and $172.0 \mathrm{~cm} ; 85.04$ and $73.60 \mathrm{~kg}$ ) completed 100 braking trials across three days on a mixture of flat, gravel roads and flat, paved roads while riding a bicycle outfitted with a validated brake power meter (Figure 1) at both the front and rear brakes of the bicycle (Miller et al., 2017a). For the functioning of this brake power meter, hollow aluminium blocks (Figure 1A) were fitted to a mountain bike on the standard brake caliper mounting posts. Within these blocks, stainless steel rods (Figure 1B) were fixed (Figure 1C) perpendicular to the braking surface between an S-Type load cell (Figure 1D; PT4000, PT Global, NZ) and a separate solid aluminium block (Figure 1E) on which the brake caliper (Figure 1F; SLX, Shimano, Japan) was attached. The load cells were fixed to the aluminium blocks on the distal end, but allowed to slide proximally

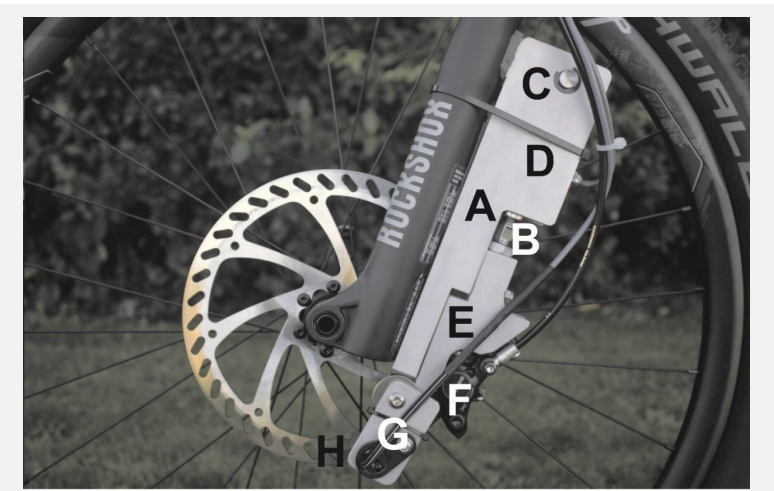

Figure 1. Front brake power meter mounted on bicycle fork. (A) machined aluminium block mounted to standard bicycle mounting posts; (B) stainless steel rod; (C) stainless steel fixing pin for load cell; (D) load cell housed within aluminium block; (E) sliding aluminium block with $(F)$ brake calliper mounted; $(G)$ magnetometer; (H) brake rotor 
where attached to the brake caliper, thus allowing the load cell to sense the movement of the brake caliper when the brake lever was squeezed and the pads were in contact with the brake rotor, which was indicative of torque. Brake pads interacted with $203 \mathrm{~mm}$ brake rotors (Figure 1H; Alligator, Taiwan) which were attached to standard 6-bolt hubs torqued to manufacturer's specifications. A magnetometer (Figure 1G) sensed the leading edge of 36 evenly spaced holes in the rotors for the measurement of velocity every $6.46 \mathrm{~cm}$ travelled, thus functioning at a higher resolution when compared with commercially available speedometers and spoke magnets. Data was collected on a stand-alone batterypowered data logger (DI-710-UHS, DATAQ Instruments, Akron Ohio, USA) attached to the bicycle's handlebar. Total bicycle mass including pedals, brake power meter and data logger was $17.28 \mathrm{~kg}$ (Seca 799, Birmingham, UK). All braking was done while coasting in a straight line with the participant seated on the saddle in a neutral riding posture. The participants were instructed to complete a mixture of skids and non-skids, but given no limitation on how to brake otherwise; this ensured that there was a mixture of front and rear brake utilization and importantly, several non-skidding events to add to the analysis. The participants were further instructed to skid across a wide range of distances to ensure that the model could be validated within and beyond the distances a rider would skid during actual recreational riding or MTB racing. For each test session, the bicycle's tire pressure was set to a standardized pressure of 0.34 psi per kg of the participants' mass with clothing and helmet.

Rear brake power was calculated in accordance with Eq. 6 . Front brake power was calculated as the product of front wheel angular velocity and front brake torque. Brake work was calculated by integrating the product of the sum of front brake power and rear brake power. All data were sampled at $128 \mathrm{~Hz}$. To calculate the total energy removed from the bicycle-rider system, estimates of aerodynamic drag and rolling resistance were added to brake work (Eq. 7-9), where adjusted energy removed calculated rear brake power using Eq. 5. Adjusted and non-adjusted total energy removed were compared with the change in kinetic energy given,

$$
W_{B}+E_{r r}+E_{d}=\Delta E_{K}
$$

Where, $W_{B}$ is brake work, $E_{r r}$ is rolling resistance, $E_{d}$ is energy lost to aerodynamic drag and $\Delta E_{K}$ is the change in kinetic energy (Miller et al., 2017a).
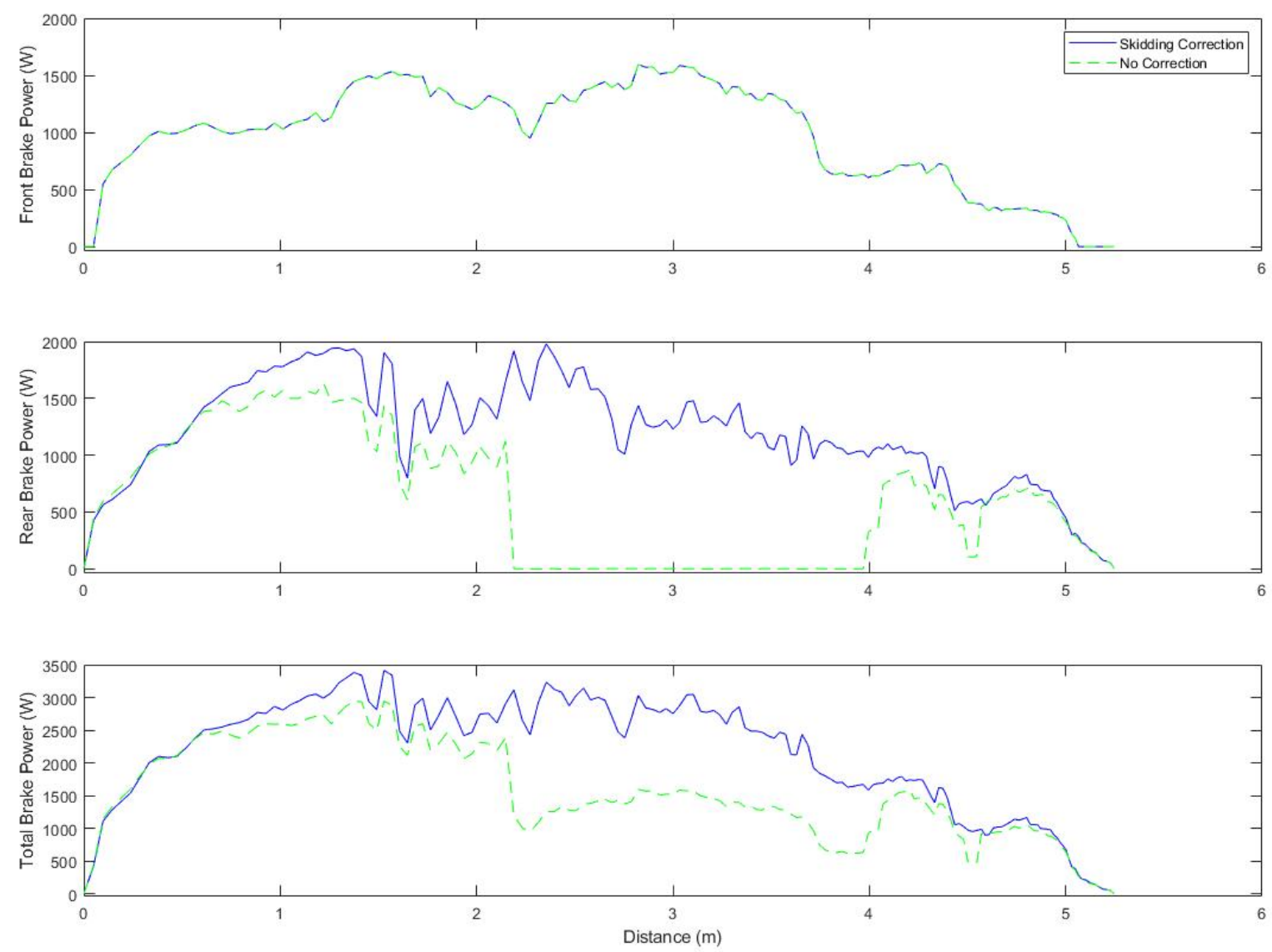

Figure 2. An example of Front Brake Power (TOP), Rear Brake Power (MIDDLE) and Total Brake Power (Front + Rear Brake Power; BOTTOM), before and after using the skidding correction. 
For rolling resistance, the predicted energy loss was

$$
\begin{gathered}
E_{r r}=m g \mu_{r r} d \\
\text { (Eq. 8) }
\end{gathered}
$$

where, $m$ is the mass of the rider plus bike, $g$ is the gravitational constant, $\mu_{r r}$ is the rolling resistance coefficient, and $d$ is the distance travelled. For an estimate of the rolling resistance coefficient a value of 0.0218 was used based on Bertucci et al. (2013).

Energy lost to aerodynamic drag was calculated as,

$$
E_{d}=\frac{1}{2} c_{d} A \rho v^{2} d
$$

where, $c_{d}$ is the drag coefficient, $A$ is the frontal area, $p$ is air density, $v$ is the average velocity during braking, and $d$ is the distance travelled. Air density was estimated at $1.2250 \mathrm{~kg} / \mathrm{m}^{3}$ for each test session.

The effective frontal area $c_{d} A$ was estimated using the equation from Bertucci et al. (2013).

$$
c_{d} A=-0.189+.304 h
$$

where, $h$ is the rider's height.

The change in kinetic energy was calculated as

$$
\Delta E_{K}=\left[\left(\frac{1}{2} m v_{2}^{2}\right)-\left(\frac{1}{2} m v_{1}^{2}\right)\right]+\left[\left(\frac{1}{2} \mathrm{I} \omega_{2}^{2}\right)-\left(\frac{1}{2} \mathrm{I} \omega_{1}^{2}\right)\right]
$$

where, $m$ is the combined mass of rider and bike, $v$ is the average velocity throughout the trial, $\omega$ is angular velocity, and I is the moment of inertia. I was calculated from

$$
\mathrm{I}=m r^{2}
$$$$
\text { (Eq. 12) }
$$

where, $m$ is the combined mass of the tyre, tube and rim for both wheels and $r$ is the distance between the axle centre and ground when the tyre was compressed at standardized pressure.

Skidding work $\left(W_{s}\right)$ was calculated as the difference between the integral of rear brake power calculated using the angular velocity of the front and rear wheels separately given,

$$
W_{s}=\int \tau_{\mathrm{r}} \omega_{\mathrm{f}}-\int \tau_{\mathrm{r}} \omega_{\mathrm{r}}
$$$$
\text { (Eq. 13) }
$$

The coefficient of determination $\left(\mathrm{r}^{2}\right)$ was calculated to determine the relationship between the change in kinetic energy and estimated energy loss of the bicycle-rider system during all braking trials. Paired student's t-tests were completed between data sets. Bland-Altman plot were created comparing the average estimated brake work and the change in kinetic energy on both surfaces. Plots of front and rear brake power traces were created to highlight the shortcomings of relying on the angular velocity of the rear wheel to calculate brake power during skidding. Analyses were completed using GraphPad Prism 7.00 (GraphPad Software, San Diego California, USA) or Matlab R2011b (The MathWorks, Inc., Natick Massachussetts, USA), with the alpha value set at 0.05 . All methodology in this study meets the ethical standards of this journal (Harris \& Atkinson, 2011).

The data of the protocols were tested for normality and homogeneity of variance and turned out to be not normally distributed. Thus, the analysis of differences between the different power output intensities (i.e. temperature, heart rate) were assessed with paired (nonparametric) Wilcoxon tests. Significance was set at $\mathrm{p} \leq$ 0.05 . Data are presented as mean values \pm standard deviation.

Spearman correlation coefficients were used to determine significant relationships between the cutaneous muscle temperature and the heart rate during the two parts of the tests (constant intensity at $100 \mathrm{~W}$ and from incremental part from 150 to $250 \mathrm{~W}$ )

All the statistics were performed with Statsoft Statistica V7.1 software (Johannesburg, South Africa).

\section{Results}

Mean \pm SD and range of braking event descriptive data are highlighted in Table 1. The change in kinetic energy and estimated energy loss exhibited a very strong, positive correlation $\left(\mathrm{r}^{2}=0.955 ; \mathrm{p}<0.0001\right.$; Figure $\left.2 \mathrm{~A}\right)$ and there was no significant difference between these two variables when braking events were performed on a flat, paved surface $\left(t_{(45)}=0.035 ; p=0.972\right)$. When performed on a flat, gravel surface, the change in kinetic energy and estimated energy loss were significantly different $\left(\mathrm{t}_{(53)}=3.445 ; \mathrm{p}=0.001\right)$ but exhibited a strong, positive correlation $\left(\mathrm{r}^{2}=0.702 ; \mathrm{p}<0.0001\right.$; Figure $\left.2 \mathrm{~B}\right)$. 


\section{(A)}
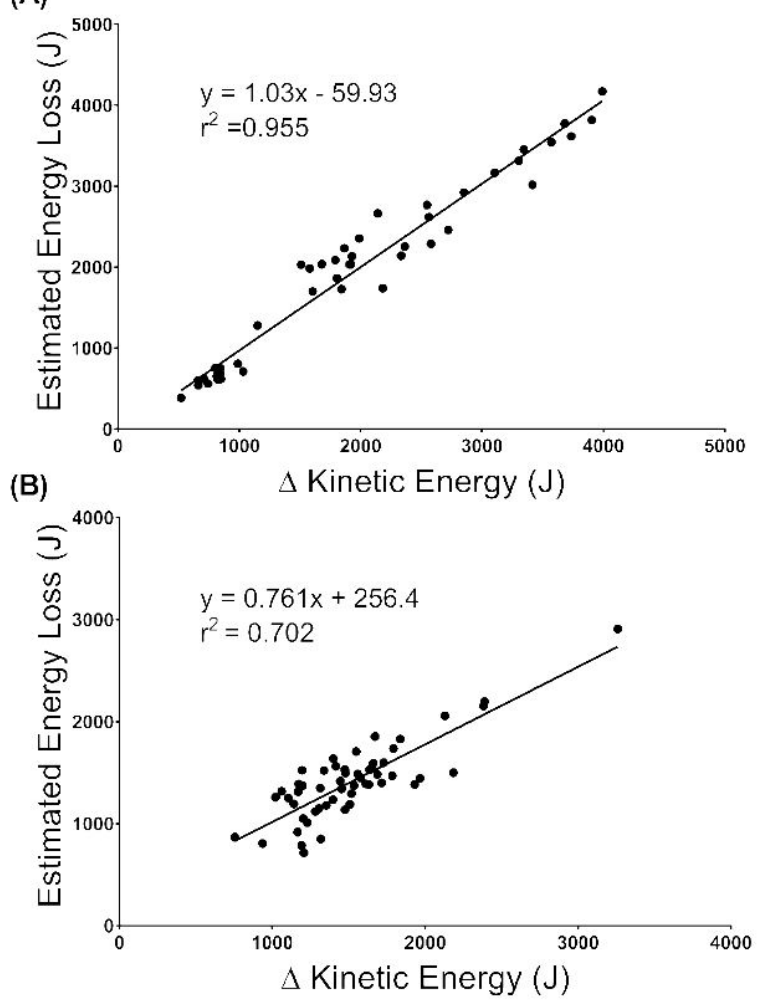

Figure 3. Correlation between the change in kinetic energy and estimated energy loss of the bicycle-rider system for skidding on (A) a flat, paved-road and $(\mathrm{B})$ a flat, gravel path.
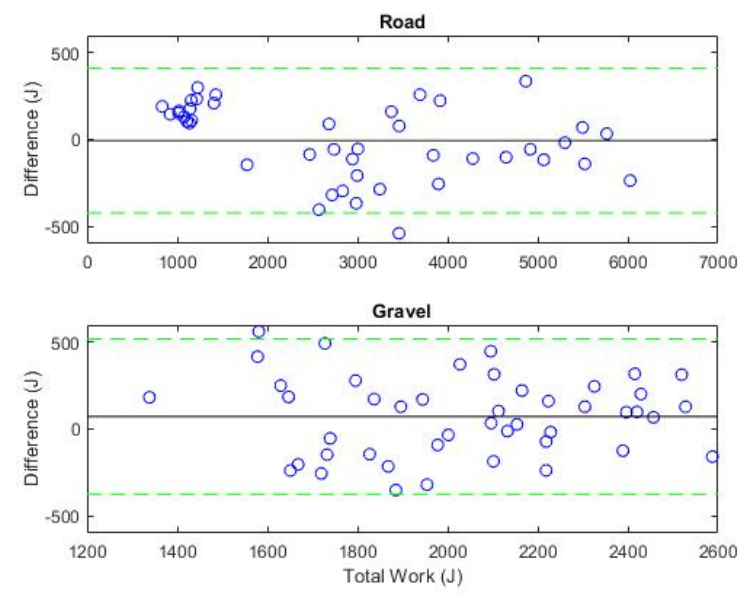

Figure 4. Bland-Altman plot comparing the average estimated brake work and the change in kinetic energy on both gravel and paved surfaces.

When all 100 values measured on paved and gravel surfaces were combined, there was no significant difference between the change in kinetic energy and estimated energy loss of the bicycle-rider system (1700.2 versus $1637.5 \mathrm{~J}$, respectively; $\mathrm{p}=0.0095$ ).

\section{Discussion}

The aim of this study was to validate a method to calculate the energy losses during rear wheel skidding on a bicycle equipped with a brake power meter. Rear brake power was calculated as the product of rear wheel torque and the angular velocity of the front wheel. It was hypothesized that the estimated energy removed from the bicycle-rider system would not be different than the change in kinetic energy of the bicycle-rider system, and that the two measurements would have a strong correlation. The findings of the present investigation support the hypothesis on both road and off-road surfaces across a range of speeds, however indicate some difficulties in using this method on gravel. As highlighted in Figure 2, the presently suggested brake power calculation is able to quantify brake power in the rear brake during skidding that was previously unmeasurable. When skidding on paved surfaces, the sum of estimations of rolling resistance, aerodynamic drag and brake work is not different than the change in kinetic energy of the bicycle-rider system. The correlation between these two values is very strong (Figure 3A). This supports the hypothesis of the present investigation on the highly controllable paved surfaces. In the previous brake power meter validation study, riding on gravel surfaces highlighted some additional energy losses are occurring that cannot be measured (Miller et al., 2017a). Possibilities such as the deformation of the tyres on the uneven surface and the movement of the dirt underneath the tyres were suggested to explain error in braking measurements on gravel. However, present error in estimations measured during skidding on gravel exceeds those previously recorded (Figure 3B). Anecdotally, skids on gravel surface appeared to cause the rear wheel to skid laterally to a greater degree than skids on the paved surface. Thus, one possible explanation for the difference in values on the gravel surface could be due to difficulties in tracking the linear speed of the bicycle-rider system. It is possible that this could be solved with technology such as a GPS device, however most consumer devices report values at only $1 \mathrm{~Hz}$ and have a high degree of variability in measurment (Wing et al., 2005). Nevertheless, the Bland-Altman plot (Figure 4) indicates strong agreement between measures on both gravel and paved surfaces.

While skidding has not been previously investigated, the magnitude of work done during skidding can be significant. This data set highlights a mean of $490 \mathrm{~J}$ across all braking events and $3000+\mathrm{J}$ recorded as the maximum value on paved surfaces (Table 1). Given these findings, the total rear brake work recorded during cycling with a brake power meter is underestimated when utilizing previous methods. Highly skilled users have provided anecdotes that skidding at opportune times in mountain biking may help to change the direction of the bicycle, and the present method can help to quantify the effect of braking during these skids.

A limitation to the present investigation is the method utilised to calculate the velocity of the bicycle, which may have introduced error when skidding and sliding on gravel. While similar methods such as a magnet on the wheel of the bicycle has been utilised to calculate the speed for many years and the original brake power meter validated this method for use when calculating front and rear brake power during non-skids, present values could have been enhanced by using highly accurate tools to measure the actual speed of the bicycle between two 
points, such as a set of timing gates or encoders. However, this study assessed skidding during braking events within a wide range of distances and speeds, which would have made timing gates difficult to use due to rider reaction times. Moreover, the high sampling speeds of the present method made the identification of skidding events and energy differences highly resolute. Thus, the findings in the present study are highly practical for the future of commercially available cycling analysis tools. The authors however do recommend future research should investigate more accurate - but still highly resolute - methods for calculating the linear velocity of the bicycle.

\section{Practical applications}

The present findings highlight that brake power can be calculated as the product or rear wheel torque and the angular velocity of the front wheel, which is able to reflect the energy losses of the bicycle during skidding across a range of distances-whether skidding or not. To accurately assess energy loss due to braking during real cycling experience, the authors suggest that rear brake power be calculated as at present. In the future, it is likely important to quantify of the amount of work done through skidding during real cycling, and to assess how skidding impacts performance and practical skid distances while mountain biking.

\section{Conflict of interest statement}

Matthew C Miller and Philip W Fink hold intellectual property protecting a bicycle brake sensor.

\section{References}

1. Bertucci, W. M., Rogier, S., \& Reiser, R. F. (2013). Evaluation of aerodynamic and rolling resistances in mountain-bike field conditions. Journal of sports sciences, 31(14), 1606-1613.

2. Chidley, J. B., MacGregor, A. L., Martin, C., Arthur, C., \& Macdonald, J. H. (2014). Characteristics Explaining Performance in Downhill Mountain Biking. International Journal of Sports Physiology and Performance.

3. Harriss DJ, Atkinson G. Update - Ethical Standards in Sport and Exercise Science Research. Int J Sports Med 2011; 32: 819-821

4. Hurst, H. T., \& Atkins, S. (2006). Power output of fieldbased downhill mountain biking. Journal of Sports Sciences, 24(10), 1047-1053.

5. Impellizzeri, F. M., \& Marcora, S. M. (2007). The physiology of mountain biking. Sports Medicine, 37(1), 59-71.

6. Lopes, B., \& McCormack, L. (2010). Mastering mountain bike skills. Champaign, Illinois: Human Kinetics.

7. Macdermid, P. W., Fink, P. W., Miller, M. C., \& Stannard, S. (2017). The impact of uphill cycling and bicycle suspension on downhill performance during cross-country mountain biking. Journal of sports sciences, 35(14), 1355-1363.

8. Miller, M. C., Fink, P. W., Macdermid, P. W., Perry, B. G., \& Stannard, S. R. (2017a). Validity of a device designed to measure braking power in bicycle disc brakes. Sports Biomechanics, 1-11.

9. Miller, M. C., Macdermid, P. W., Fink, P. W., \& Stannard, S. R. (2017b). Performance and physiological effects of different descending strategies for crosscountry mountain biking. European journal of sport science, 17(3), 279-285.

10. Miller, M. C., Fink, P. W., Macdermid, P. W., \& Stannard, S. R. (2018a). Quantification of brake data acquired with a brake power meter during simulated cross-country mountain bike racing. Sports Biomechanics, IN PRESS.

11. Miller, M. C., Fink, P. W., Macdermid, P. W., Allen, D., \& Stannard, S. R. (2018b). Braking and performance characteristics of experienced and inexperienced mountain bikers navigating an isolated off-road turn using a brake power meter. International Journal of Performance Analysis in Sport, 1-12.

12. Wing, M. G., Eklund, A., \& Kellogg, L.D. (2005). Consumer-grade global positioning system (gps) accuracy and reliability. Journal of Forestry, 103(4), 169. 